
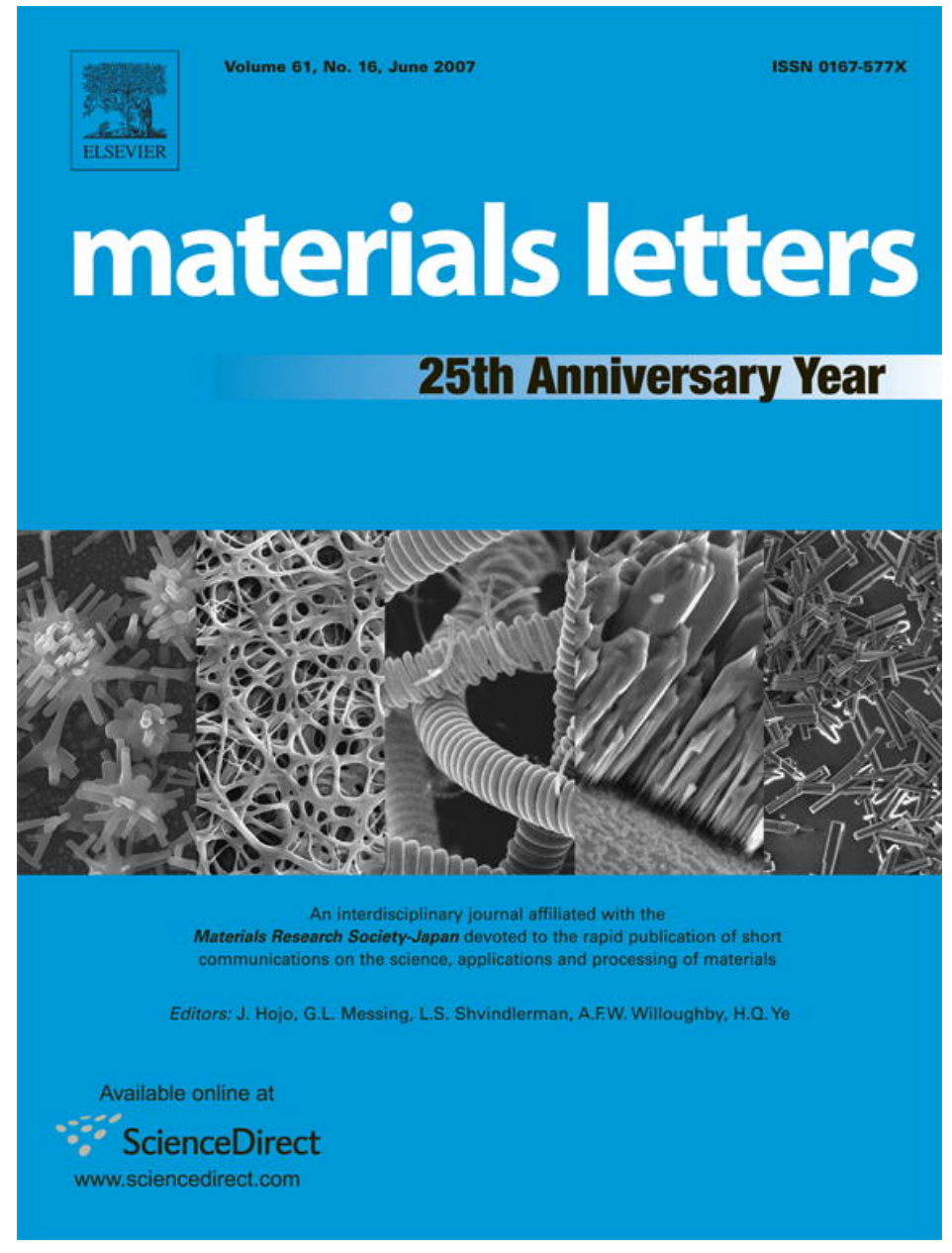

This article was originally published in a journal published by Elsevier, and the attached copy is provided by Elsevier for the author's benefit and for the benefit of the author's institution, for non-commercial research and educational use including without limitation use in instruction at your institution, sending it to specific colleagues that you know, and providing a copy to your institution's administrator.

All other uses, reproduction and distribution, including without limitation commercial reprints, selling or licensing copies or access, or posting on open internet sites, your personal or institution's website or repository, are prohibited. For exceptions, permission may be sought for such use through Elsevier's permissions site at: 


\title{
Calcium-phosphate derived from mineralized algae for bone tissue engineering applications
}

\author{
Joaquim M. Oliveira ${ }^{\mathrm{a}, \mathrm{b}, *}$, Jessica M.R. Grech ${ }^{\mathrm{a}, \mathrm{b}}$, Isabel B. Leonor ${ }^{\mathrm{a}} \mathrm{b}$, \\ João F. Mano ${ }^{\mathrm{a}, \mathrm{b}}$, Rui L. Reis ${ }^{\mathrm{a}, \mathrm{b}}$ \\ a 3B's Research Group, Biomaterials, Biodegradables and Biomimetics, Campus de Gualtar, 4710-057, Braga, Portugal \\ b Department of Polymer Engineering, University of Minho, Campus de Azurém, 4800-058, Guimarães, Portugal \\ Received 26 July 2006; accepted 21 November 2006 \\ Available online 8 December 2006
}

\begin{abstract}
In this work, several routes are described towards obtaining pure inorganic phases derived from Coralline officinallis red algae. The scanning electron microscopy studies have shown that it becomes possible not only to eliminate the undesired organic phase, but also to preserve or tailor the red algae typical microporosity. X-ray diffraction analysis was used to investigate the phase content of the red algae before and after performing the different treatment routes. Hydroxyapatite nanocrystallites were obtained after converting the coralline calcium carbonate skeleton by means of combining thermal and chemical routes. These results were confirmed by Fourier transform infra-red spectroscopic analysis. The processing routes herein described are very promising in order to design bioceramics of algae origin that might find useful applications as bone fillers and tissue engineering scaffolds.
\end{abstract}

(C) 2006 Elsevier B.V. All rights reserved.

Keywords: Calcium-phosphate; Coralline officinallis; Hydroxyapatite; Mineralized red algae; Bone tissue engineering

\section{Introduction}

Porous ceramic particulates made from natural red algae (e.g. Coralline officinallis) are promising in terms of its biocompatibility [1], osteoconductivity [2], availability and porous architecture [3]. As result they were proposed for skeletal replacement/regeneration applications [4-6]. However, it has been reported $[2,7,8]$ that coralline calcium carbonate skeletons (aragonite or calcite forms) are unsuitable for most applications due to its fast resorption [9] and poor stability. Treatment routes to convert the hard calcium carbonate skeleton of mineralized algae into more stable structures should then be explored. This goal may be accomplished by conversion of the calcium carbonate skeleton into calcium-phosphates (Ca-Ps) [3]. As a result, more stable synthetic ceramics can be obtained, where

\footnotetext{
* Corresponding author. 3B's Research Group, Biomaterials, Biodegradables and Biomimetics, Campus de Gualtar, 4710-057, Braga, Portugal. Tel.: +351 253 604782; fax: +351253604498.

E-mail address: miguel.oliveira@dep.uminho.pt (J.M. Oliveira).
}

their composition and porous architecture may be tailored in order to control the correspondent resorption rate.

Hydrothermal exchange (Eq. (1)) has been shown to be a reliable strategy to convert the hard calcium carbonate skeleton of algae into hydroxyapatite [3].

$$
\begin{aligned}
& 10 \mathrm{CaCO}_{3}+6\left(\mathrm{NH}_{4}\right)_{2}+2 \mathrm{H}_{2} \mathrm{O} \rightarrow \mathrm{Ca}_{10}\left(\mathrm{PO}_{4}\right)_{6}(\mathrm{OH})_{2} \\
& \quad+6\left(\mathrm{NH}_{4}\right)_{2} \mathrm{CO}_{3}+4 \mathrm{H}_{3} \mathrm{CO}_{3}
\end{aligned}
$$

However, by this route only a partial conversion of coralline calcium carbonate to hydroxyapatite is achieved. Moreover, the pore architecture is often destroyed upon the conversion process $[3,10]$, which may compromise both biological and mechanical properties of such materials.

This work aims to develop novel routes to convert the calcium carbonate skeleton of $C$. officinallis red algae into calcium-phosphates, while maintaining its native microstructure and mechanical strength that have been shown [4] to be useful for applications as bone fillers and as bone tissue engineering scaffolds. 


\section{Experimental}

\subsection{Preparation of the calcium-phosphate particulates derived from red algae $C$. officinallis}

Particulates of the red algae C. officinallis were used as a source of calcium carbonate. Several approaches were tested in order to eliminate the organic phase of the algae and convert the calcium carbonate skeleton into $\mathrm{Ca}-\mathrm{Ps}$, and at the same time maintaining its morphology. The preparation of the calciumphosphates was performed by means of a thermal, chemical, and a combination of both treatments. The algae particulates were burned in the furnace (FornoCerâmica, Type EB4, Portugal) at $400{ }^{\circ} \mathrm{C}$ with a ramp rate of $4{ }^{\circ} \mathrm{C} \mathrm{min}^{-1}$ for different periods of time (dwelling time), followed by natural cooling inside the furnace. The algae particulates were also treated chemically by soaking them into a hydrofluoric acid (Aldrich, 48\%, Germany) for 5 days. The preparation of calcium-phosphate materials was carried out by means of mixing the obtained calcium carbonate skeleton of the algae with several sources of phosphates, namely: (i) ammonium phosphate dibasic (Sigma, 98\%, Germany), (ii) ortho-phosphoric acid (Panreac, $85 \%$, Spain), and (iii) sodium pyrophosphate decahydrate (Sigma, Germany), for several days. The final materials were filtered, washed abundantly with deionised water and dried in an oven at $60{ }^{\circ} \mathrm{C}$ for further characterization.

\subsection{Scanning electron microscopy}

The microstructure of $C$. officinallis red algae before and after performing the several conversion treatments was investigated using a scanning electron microscope attached with an energy dispersive electron probe X-ray analyzer (SEM-EDS, Leica Cambridge S-360, UK). All materials were coated with carbon (Polaron SC 508 coater, Fisons Instruments, UK) for elemental analysis, followed by gold (Polaron SC 502 coater, Fisons Instruments, UK), prior to microstructure observation.

\subsection{X-ray diffraction measurements}

A X-ray diffractometer (XRD, Philips PW 1710, The Netherlands) was used to assess the crystallinity and phase content of $C$. officinallis red algae as received and after performing the several treatment routes. All XRD patterns were examined in the region of $2^{\circ}$ to $65^{\circ}$ with a step size $0.02^{\circ}$ for $2 \theta$ and scan speed of $0.6^{\circ} \mathrm{min}^{-1}$.

\subsection{Fourier transform infra-red spectroscopy}

A Perkin-Elmer 1600 series spectrophotometer (FTIR, Perkin-Elmer, UK) allowed the investigation of the chemical changes of $C$. officinallis red algae as received and after performing the several treatment routes. Transparent sample/ $\mathrm{KBr}$ discs (ratio 1:10) were prepared by means of mixing the powders and then uniaxially pressing. All spectra were collected over a region of $4400-450 \mathrm{~cm}^{-1}$, with a minimum of 32 scans and resolution of $2 \mathrm{~cm}^{-1}$.

\section{Results and discussion}

The SEM studies have shown that the red algae $C$. officinallis possess an ordered and interconnected microporosity (Fig. 1). From Fig. $1 \mathrm{~A}-\mathrm{B}$ it is possible to observe the well defined orientation of tubular pores with diameter of $\sim 5 \mu \mathrm{m}$. The EDS analysis revealed the presence of calcium, oxygen, carbon, magnesium, aluminium, silicon, sulphur, chloride, phosphorous, potassium and iron elements as it is shown in the Fig. 1C. On the other hand, the external morphology consists of a regular round porous matrix with pores of similar dimension and shape (Fig. 1D-E). The EDS analysis also revealed the
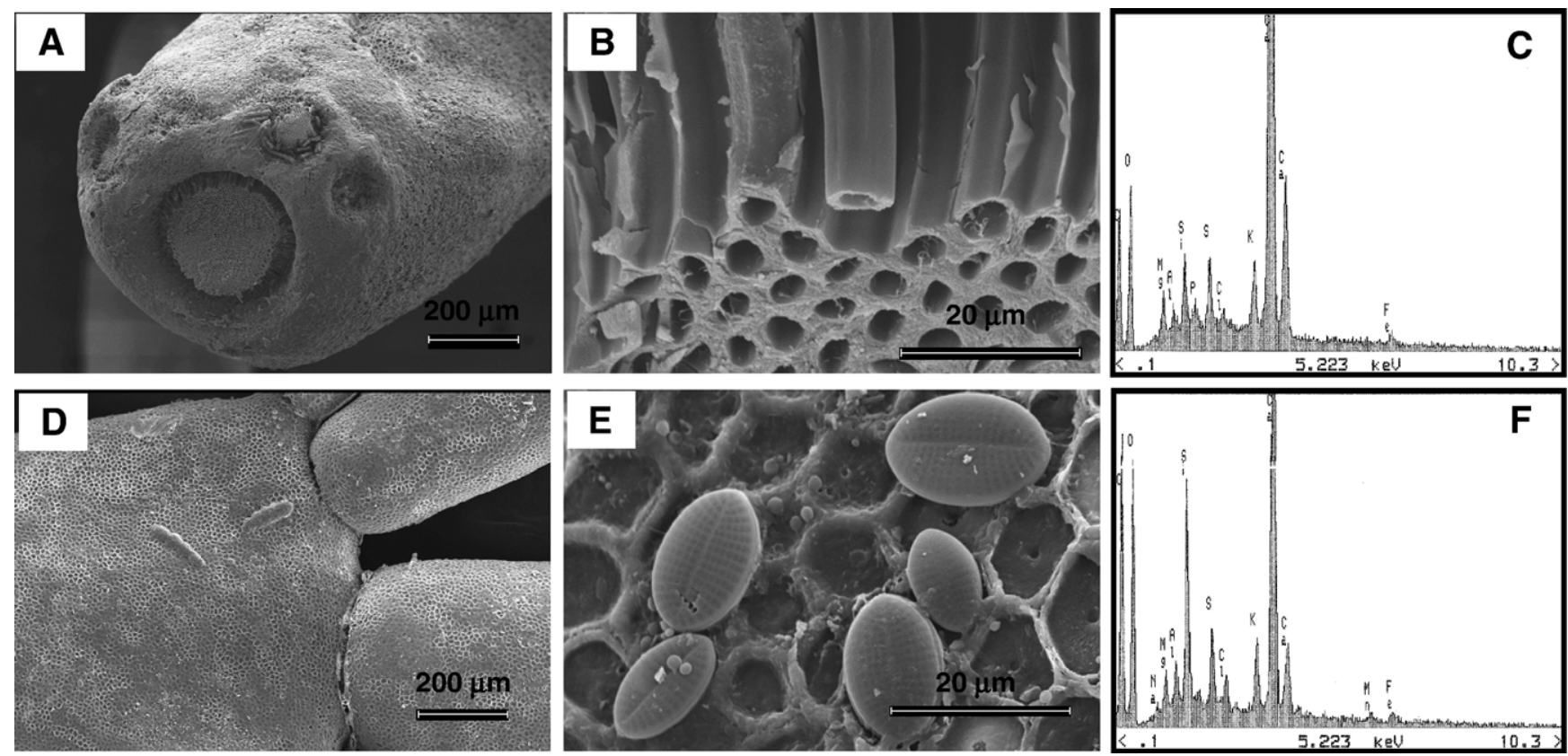

Fig. 1. SEM micrographs and respective EDS spectra of Coralline officinallis: (A-C) internal, and (D-F) external views. 

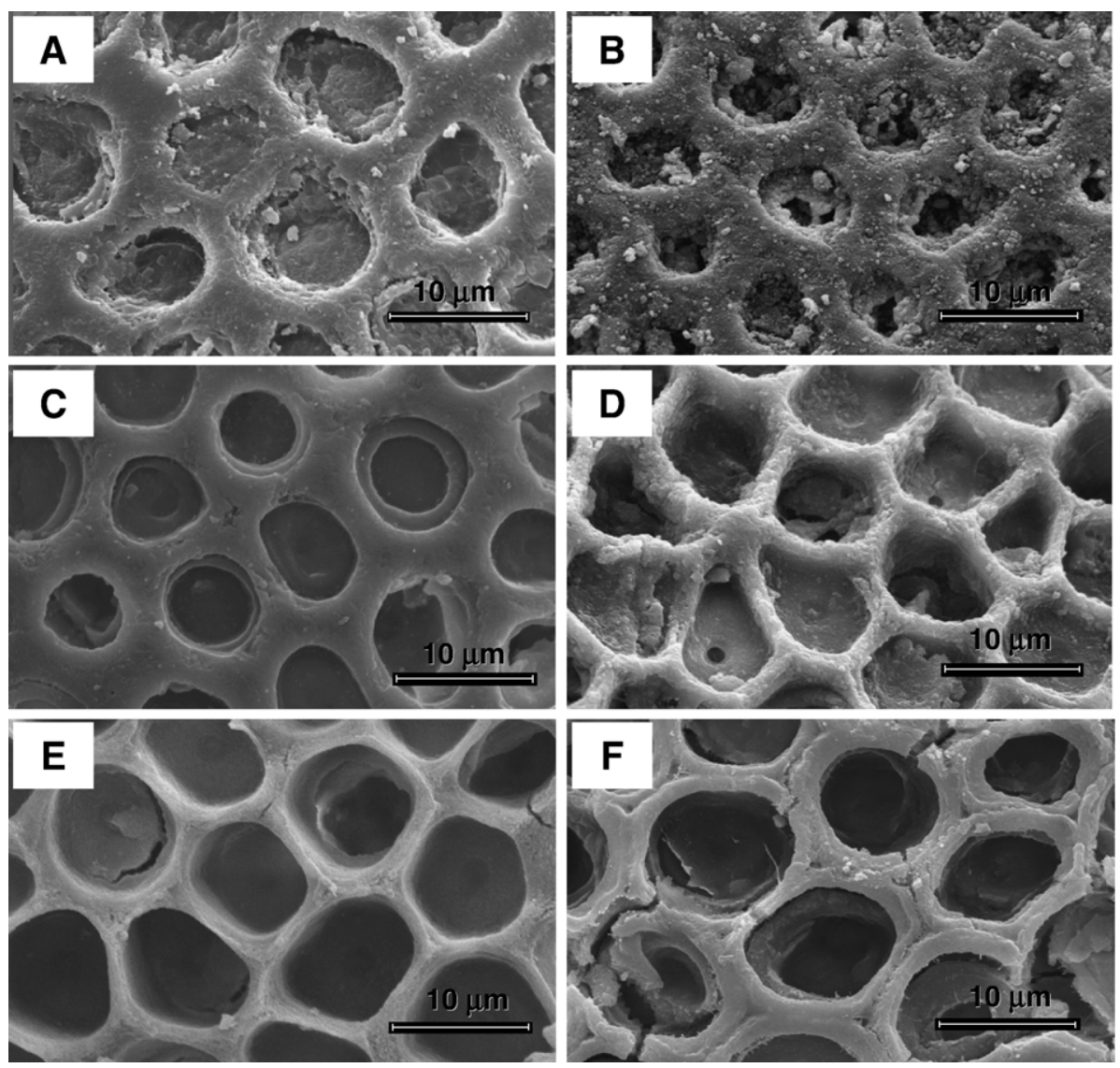

Fig. 2. SEM micrographs of Coralline officinallis: (A) as received, (B) after $6 \mathrm{~h}$ at $400{ }^{\circ} \mathrm{C}$, and after different chemical treatments with $(\mathrm{C}) \mathrm{Na}_{4} \mathrm{P}_{2} \mathrm{O}_{7} \cdot 10 \mathrm{H}_{2} \mathrm{O}$, (D) $\mathrm{H}_{3} \mathrm{PO}_{4}$, (E) $\mathrm{H}_{3} \mathrm{PO}_{4}+\left(\mathrm{NH}_{4}\right)_{2} \mathrm{HPO}_{4}$, and (F) $\mathrm{HF} 48 \%$.

presence of calcium, oxygen, carbon, magnesium, sulphur, chloride, aluminium, silicon, phosphorous, potassium and iron elements (Fig. 1F), but in a lower content than in the interior.

In this study, several approaches have been explored to eliminate the organic phase of coralline, namely the thermal and chemical routes. Figs. 2 and 3 show the microstructure of coralline particulates before and after the treatments as well as the respective XRD patterns. From Fig. 2B it can be observed that the coralline particulates preserved their typical morphology, when treated at a temperature of $400{ }^{\circ} \mathrm{C}$ for $6 \mathrm{~h}$. This temperature was chosen since it is known that higher temperatures decompose all carbonate phases [10]. The XRD pattern demonstrates that the decomposition of the calcium carbonate was prevented (Fig. 3B). In addition, the SEM images also demonstrated that coralline particulates presented different morphologies when performing different treatments. By soaking the coralline particulates in different solutions it was not only possible to eliminate the organic phase but also to control its microstructure. Actually, it was possible to eliminate the organic phase, while preserving the typical coralline microporosity (Fig. 2C). This study also shows that chemical treatments are more effective than a thermal route towards obtaining more "cleaner" particulates, despite the fact that in some cases the treatment appears to destroy the pore structure and induce the formation of fractures (Fig. 2D-F). This may be explained by the fact that the acids also partially dissolve the inorganic material [11].

Fig. 3 shows the XRD patterns of $C$. officinallis before and after carrying out the thermal and chemical treatments. Comparing the XRD pattern of $C$. officinallis as received with that of the red algae after the thermal treatment at $400{ }^{\circ} \mathrm{C}$, it is possible to observe a peak broadening which can be due to a subtle phase transformation that occurs (Fig. 3B). Although, further studies are needed to clarify this issue. On the other hand, the XRD patterns revealed that decomposition of certain carbonate phases occurs after performing the chemical treatments (Fig. 3C-F). Once, this observation may be a consequence of the partial dissolution of the calcium carbonate followed by the reprecipitation.

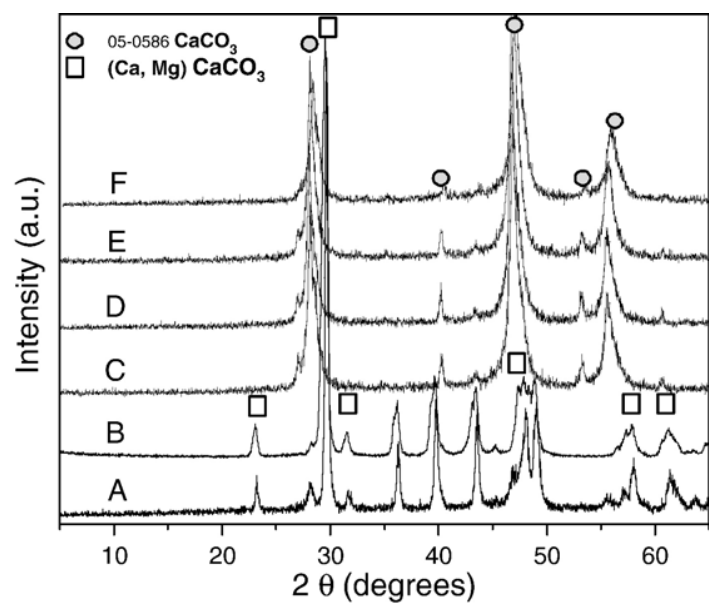

Fig. 3. XRD pattern of Coralline officinallis: (A) as received, (B) after $6 \mathrm{~h}$ at $400{ }^{\circ} \mathrm{C}$, and after different chemical treatments with (C) $\mathrm{Na}_{4} \mathrm{P}_{2} \mathrm{O}_{7} \cdot 10 \mathrm{H}_{2} \mathrm{O}$, (D) $\mathrm{H}_{3} \mathrm{PO}_{4}$, (E) $\mathrm{H}_{3} \mathrm{PO}_{4}+\left(\mathrm{NH}_{4}\right)_{2} \mathrm{HPO}_{4}$, and (F) $\mathrm{HF} 48 \%$. 

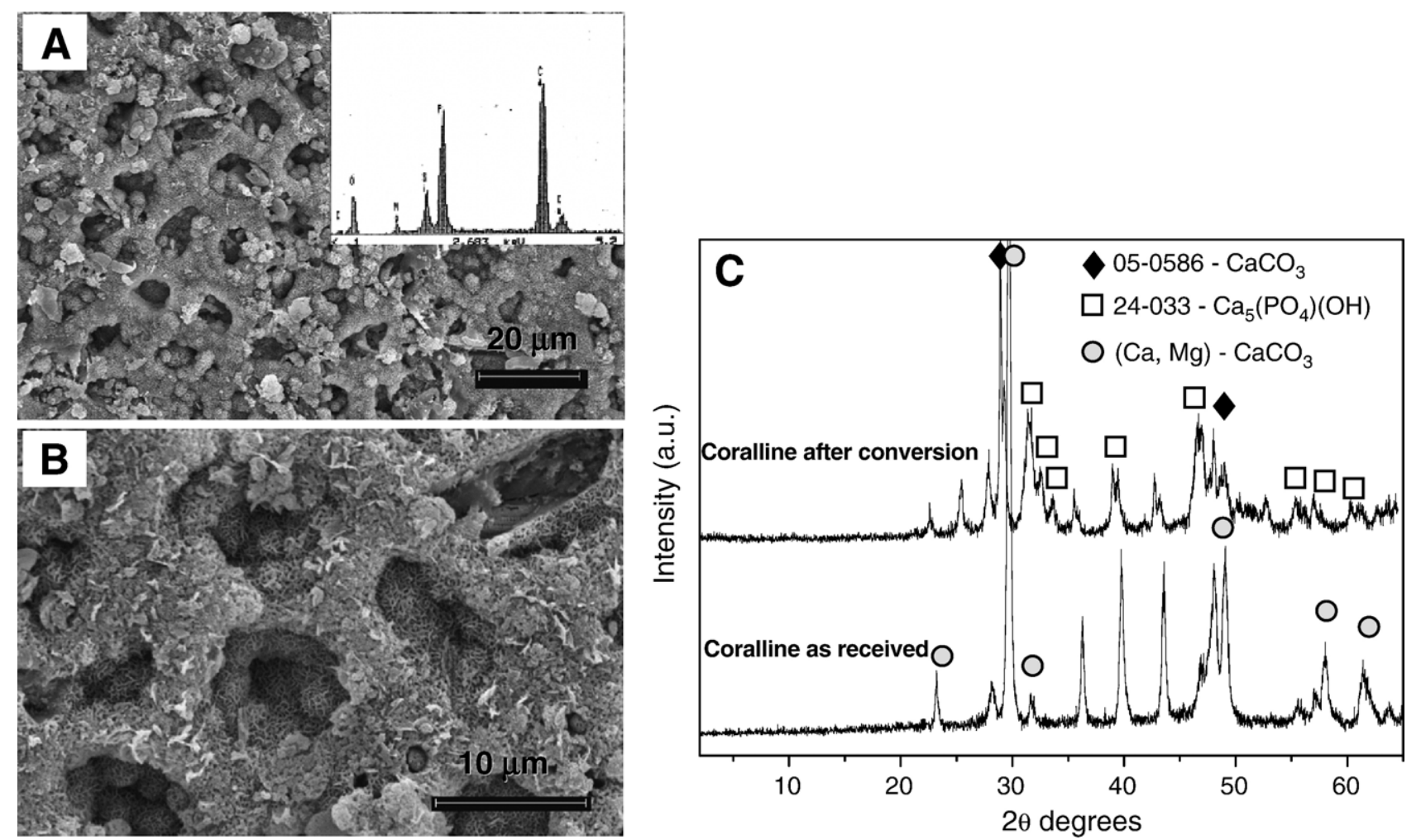

Fig. 4. SEM micrographs of Coralline officinallis after performing the heat treatment $\left(400{ }^{\circ} \mathrm{C}\right)$ followed by chemical treatment $\left(\left(\mathrm{NH}_{4}\right)_{2} \mathrm{HPO}_{4}\right.$, 28 days $)(\mathrm{A}-\mathrm{B})$, and respective XRD pattern comparing to that of coralline as received $(\mathrm{C})$.

In addition, a combined route (thermal and chemical) was also carried out in order to try to obtain coralline particulates possessing not only a pure inorganic phase but also to convert the calcium carbonate skeleton into Ca-Ps. As it is shown in Fig. 4A-B, this combined treatment permitted the partial conversion of the calcium carbonate skeleton of the origin red algae into hydroxyapatite (HA) nanocrystallites. Complementarily, the EDS analysis revealed that it is also possible to obtain coralline particulates of different compositions with respect to elemental composition (Fig. 4A). This result is promising considering that by using these treatments it is possible to prepare

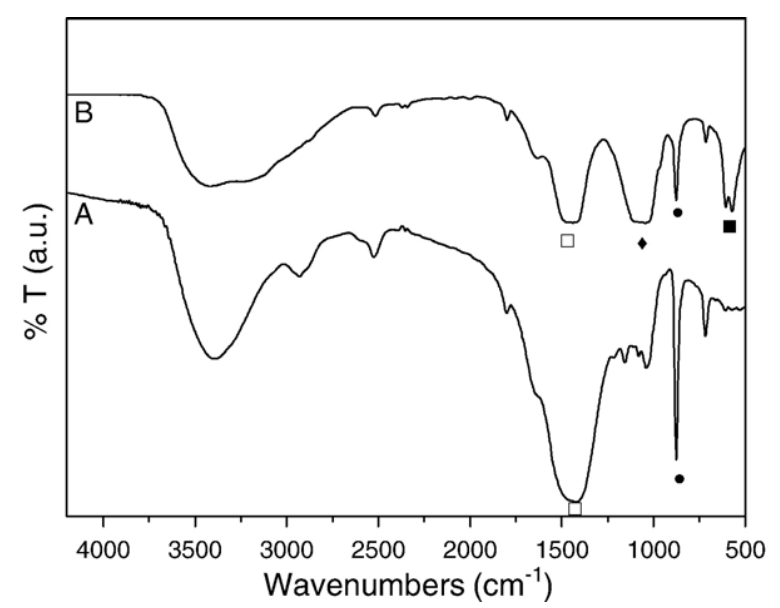

Fig. 5. FTIR spectrum of Coralline officinallis: (A) as received, and (B) after partial conversion into $\mathrm{Ca}-\mathrm{P}$ by means of using a combined route (heat treatment at $400{ }^{\circ} \mathrm{C}$ followed by chemical treatment chemical treatment $\left(\left(\mathrm{NH}_{4}\right)_{2} \mathrm{HPO}_{4}\right.$, 28 days)). different ceramic materials enriched with elements that actually are also present in bone, such as magnesium and silicon. The XRD patterns of coralline particulates before treatment (Fig. 3A) show several diffraction peaks that can be assigned to an calcite phase rich in $\mathrm{Mg}$ (Ca, $\mathrm{Mg}) \mathrm{CO}_{3}$ (ASTM JCPDS 43-0697). On the other hand, after carrying out a combined treatment (burning at $400{ }^{\circ} \mathrm{C}$ and soaking with ammonium phosphate dibasic $\left(\left(\mathrm{NH}_{4}\right)_{2} \mathrm{HPO}_{4}\right)$ for 28 days $)$, the XRD pattern clearly demonstrated the presence of not only carbonate phases but also peaks that matched with the standard file for HA (ASTM JCPDS 24-033) (Fig. 4C).

From FTIR analysis it is possible to observe the presence of typical carbonate groups of $C$. officinallis namely, the $\mathrm{CO}_{3}^{2-} v 3$ and $v 2$, the broad band at $\sim 1400 \mathrm{~cm}^{-1}(\square)$ and the sharp band at $882 \mathrm{~cm}^{-1}(\mathbf{O})$, respectively. These bands can also be detected after carrying out the combined treatment (Fig. 5B), however their intensity is lower. Additionally, phosphate groups of HA, namely the bands at 598, 559

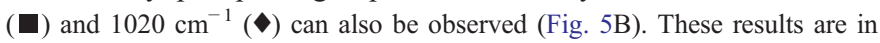
agreement with the ones obtained from SEM/EDS and XRD (Fig. 4), which demonstrated that by performing a combined treatment (thermal and chemical) it is possible to partially convert the calcium carbonate into Ca-Ps.

\section{Conclusions}

This work demonstrated that by performing a combined treatment (thermal and chemical) it became possible to convert particulates of a mineralized coralline algae calcium carbonate skeleton into calcium-phosphate material possessing hydroxyapatite nanocrystallites. Moreover, it was demonstrated that by means of using different chemical treatments it is possible to tailor the microstructure of 
coralline, and consequently other properties such as bioactivity and degradation profile. Therefore, the routes herein proposed seem very promising to develop adequate algaederived calcium-phosphate particulates to find applications as bone filler and as tissue engineering scaffolds.

\section{Acknowledgements}

The authors would like thank the financing provided by the Portuguese Foundation for Science and Technology (FCT), through funds from the POCTI and FEDER programmes. J.M. Oliveira also thanks FCT for providing the PhD scholarship (SFRH/BD/21786/2005). This work was also partially supported by the European Union funded STREP Project HIPPOCRATES (NMP3-CT-2003-505758), and carried out under the scope of the European NoE EXPERTISSUES (NMP3-CT-2004-500283).

\section{References}

[1] M.J. Doherty, G. Schlag, N. Schwarz, R.A.B. Mollan, P.C. Nolan, D.J. Wilson, Biomaterials 15 (1994) 601-608.
[2] L. Dupoirieux, V. Costes, P. Jammet, F. Souyris, Int. J. Oral Maxillofac. Surg. 23 (1994) 395-398.

[3] B. Ben-Nissan, A. Milev, R. Vago, Biomaterials 25 (2004) 4971-4975.

[4] S.W. Wolfe, L. Pike, J.F. Slade III, L.D. Katz, J. Hand Surg. 24A (1999) $816-827$.

[5] F. Chen, T. Mao, K. Tao, S. Chen, G. Ding, X. Gu, J. Oral Maxillofac. Surg. 60 (2002) 1155-1159.

[6] B.F. Shahgaldi, Biomaterials 19 (1998) 205-213.

[7] P. Jammet, F. Souyris, P. Baldet, F. Bonnel, M. Huguet, J. Cranio-MaxilloFacial Surg. 22 (1994) 103-108.

[8] B. Ben-Nissan, Curr. Opin. Solid State Mater. Sci. 7 (2003) 283-288.

[9] F. Braye, J.L. Irigaray, E. Jallot, H. Oudadesse, G. Weber, N. Deschamps, C. Deschamps, P. Frayssinet, P. Tourenne, H. Tixier, S. Terver, J. Lefaivre, A. Amirabadi, Biomaterials 17 (1996) 1345-1350.

[10] M. Sivakumar, T.S. Sampath Kumar, K.L. Shantha, K. Panduranga Rao, Biomaterials 17 (1996) 1709-1714.

[11] M.F. Barba, P. Callejas, J.O. Arzabe, J.M. Villora, J. Eur. Ceram. Soc. 23 (2003) 2893-2896. 